\title{
Perceptions of the Use of Cued Speech in an Inclusive High School Context in Quebec
}

\author{
Audrey Dupont, France Beauregard \\ Université de Sherbrooke \\ Hélène Makdissi \\ Université Laval
}

\begin{abstract}
Six students and six parents were interviewed about the use of Cued Speech (CS) in an inclusive context in Quebec, Canada. The objective of the study was to describe their perceptions of the use of the French version of Cued Speech in high school and to identify factors that could influence these perceptions. The results of the semi-structured interviews showed that CS use is often temporary but that it is helpful for developing oral and written language. It also supports inclusion, so long as certain conditions for its application are met with respect to interpreter services and interactions at school. In some circumstances, the participants found Quebec Sign Language useful to complement Cued Speech.
\end{abstract}

The inclusion of students who are deaf or hard of hearing has often been studied, but mainly from the angle of the use of sign language or of oralism (Angelides \& Aravi, 2007; Xie, Potměšil, \& Peters, 2014). However, the inclusion of students using Cued Speech (CS) has received very little research attention (Crain \& LaSasso, 2010). Even though the French equivalent of $\mathrm{CS}$-Langue française parlée complétée, $L P C$-is commonly used in francophone European countries, this communication mode is still not widely used or studied in Quebec (Office des personnes handicapées du Québec, 2005). The aim of the present study was to come to a better understanding of the inclusion of students who are deaf in Quebec who use CS. 


\section{Students Who Are Deaf or Hard of Hearing}

It has been estimated that, in Western countries, hearing losses affect nearly $10 \%$ of the population and nearly $2 \%$ of school-aged children (Schoenborn \& Heyman, 2008). In Canada, that translates into more than 23,000 children (Canada Statistics, 2010). Of the population who are deaf or hard of hearing $(\mathrm{D} / \mathrm{HH})$, approximately $92 \%$ are born of hearing parents; 8\% thus have parents who are also D/HH (Mitchell \& Karchmer, 2004). In Quebec, slightly over 1,600 school-aged children are D/HH (Ministère de l'Éducation du Loisir et du Sport, 2009).

\section{Educating Children Who Are D/HH}

To promote learning among students who are D/HH, Quebec's Education Act stipulates that a child with a handicap, such as hearing loss, has a right to free schooling until the age of 21 years, as opposed to 18 years in the general population (Gouvernement du Québec, 2011). In Quebec, school inclusion is generally achieved by means of a mainstreaming approach based on a cascade system (Ministère de l'Éducation du Loisir et du Sport du Québec, 2010). Services range from a regular classroom with support services to home schooling, with a whole spectrum of intermediate options in between.

The communication mode ${ }^{1}$ used in schooling a student who is $\mathrm{D} / \mathrm{HH}$ depends mainly on where the student lives, as services for the $\mathrm{D} / \mathrm{HH}$ are not spread evenly across the territory. For example, schooling in Quebec Sign Language (known as Langue des signes $d u$ Québec, or $L S Q$ ) is most accessible in the Montreal region because there are specialized schools in the area; whereas outside of large cities, students who are $\mathrm{D} / \mathrm{HH}$ are most often taught in regular classes and therefore in an oralist system (Office des personnes handicapées du Québec, 2005).

In the oralist context, some classes are based on students' aural-oral capacities, while others employ the linguistic support of Cued Speech (CS). In aural-oral classes, the objective is to enable the child to acquire speech, through a variety of means, using residual hearing (Office des personnes handicapées du Québec, 2005). The learner needs to understand and reproduce the sounds of the oral language. In this approach, sign language or CS cues are generally not used. In classes using CS, the objective is the same, but the means to achieve it are different. CS is a visual communication mode to help the student distinguish the different phonemes of oral language, and for that reason, is necessarily used in conjunction with the oralist approach.

\section{Cued Speech}

In the specific case of Quebec, even though there are isolated initiatives in different regions, only one school systematically teaches CS. This elementary school has a supraregional mandate, and its students come not only from the cities and towns in the regional school board, but also from the catchment areas of neighbouring school boards that do not offer those services.

\footnotetext{
${ }^{1}$ In this text, communication mode refers to the method used to exchange information. It can be oral, visual, or written.
} 
In this study, we focus particularly on CS, a visual communication mode adapted to over 60 different languages and dialects (Cornett, n.d.). To clarify the particularities of $\mathrm{CS}$, we present them within two dimensions: The social dimension is related to the acquisition of oral language and the interactions with others; the school dimension refers to the learning of reading and writing, which takes place primarily in school.

\section{Social Dimension}

For persons who are $\mathrm{D} / \mathrm{HH}$, the socio-linguistic aspect of a language is very important in their interactions, because to engage in an effective communication they need, on one hand, to understand what is said and, on the other, to make themselves understood. This is why the linguistic aspects of CS are particularly relevant in the social dimension.

Contrary to other signing communication modes, CS is a means of supporting oral language and follows the phonemic structure of the oral language as well as the sentence structure. In this way, oral language is the child's first language - the parents' languagewith CS being a visual support for that language. In CS, a manual and visual representation called a cue is attributed to each pronounced phoneme, such that phonemes producing the same labial image, e.g., [b] and [p], are not represented by the same cue. ${ }^{2}$ In this way, CS enables persons who are D/HH to learn to speak.

Studies over the past three decades have shown that systematic use of CS improves the perception of oral speech both in English (Nicholls \& Ling, 1982) and in French (Périer, Charlier, Hage \& Alegría, 1990). Other studies have also highlighted the advantages of CS in the language learning process. Researchers observed that CS led to a significant improvement in lip reading, particularly when CS was learned before starting school, regardless of the severity of their hearing loss (Aparicio, Peigneux, Charlier, Neyrat, \& Leybaert, 2012).

Thus, it appears the assistance provided by CS helps to improve the reception of speech and tends to reduce lip-reading confusions, even more so when CS is learned early (Aparicio et al., 2012). Perrier and colleagues (1990) concluded that, unlike signing communication modes, CS fosters the acquisition of oral language and leads to better oral communication. Several studies have shown that knowing the oral language fosters learning of the written language, so it follows that children who are $\mathrm{D} / \mathrm{HH}$ with a better knowledge of the targeted language are more easily able to learn to read and write (Geers \& Moog, 1989), which help them interact with their environment in an inclusive context.

\section{School Dimension}

Students learn to read and write based on their mental representations of oral language. In this respect, according to several studies, CS has been shown particularly to

\footnotetext{
${ }^{2}$ Earlier, we pointed out that CS is used in around 60 languages. As these languages do not all present the same phonemes, it should be noted that French CS does not use exactly the same cues as its counterparts, for instance, in English or Spanish. When studying English, francophone students who are deaf and their transliterators need to use the cues that are specific to English.
} 
foster the development of accurate phonological, lexical, and morpho-syntactic representations of oral language that allows children who are $\mathrm{D} / \mathrm{HH}$ to understand a message, either oral or written (Crain \& LaSasso, 2010; Leybaert, Aparicio, \& Alegria, 2011). LaSasso and Crain (2015, p. 462) concluded that CS, in "providing clear, complete visual access to English," facilitated the development of written language.

From a broader perspective, several studies emphasized that, among students who are $\mathrm{D} / \mathrm{HH}$, linguistic competencies were a key factor influencing their social inclusion (Dammeyer, 2010). Yet only few studies have specifically examined the influence of CS on the school inclusion environment (Crain \& LaSasso, 2010; Dupont, 2009). The aim of the present study was to inquire how students and their parents perceive the use of CS in an inclusion context. To this end, our research question was: What perceptions do parents and their children who are D/HH using CS have about the inclusion experience?

\section{Method}

\section{Research Design}

The specific objective of the study is to describe the perceptions of students who are $\mathrm{D} / \mathrm{HH}$ and of their parents regarding the use of CS in an inclusion context and then to identify factors that might influence those perceptions. This objective led us to adopt an interactionist perspective as described by Blumer $(1962,1969)$, in which each individual, in interaction with others, conceives, perceives, interprets, and acts in a socially constructed symbolic reality. Our framework was also inspired by the notion of perceptual fields developed by Combs (Combs, 1999; Combs, Richards, \& Richards, 1976; Combs \& Snygg, 1959). In this study, perception was defined as a socially constructed personal process through which the individual creates and interprets his own meaningful reality (Dupont, 2018). Our research focuses on perceptions regarding the use of $\mathrm{CS}$ in an inclusion context where multiple interactions occur. The qualitative methodology adopted for this study is based on the work of Denzin and Lincoln (2011) and Miles, Huberman, and Saldaña (2014), and is closely linked to the interpretive research approach. In this approach, it is of great value to grasp the sense actors attribute to their conduct, and how they live their experiences: The actors are viewed as the main contributors. This approach is entirely compatible with the use of qualitative interviews.

\section{Participants}

We conducted semi-structured interviews with six students who are $\mathrm{D} / \mathrm{HH}$ and who had learned CS, and with six of their parents. Participants were recruited through letters distributed by an association for the deaf or hard of hearing. In a snowball sampling approach, the first participants recommended other participants.

With regard to inclusion criteria, students in this study had to: (a) be diagnosed as $\mathrm{D} / \mathrm{HH}$ with no other disabilities (intellectual, language, developmental); (b) have learned to use CS; (c) have been integrated into their regular school environment for at least two years; and (d) be between the ages of 13 and 21 years. The parents in the sample were parents of the six selected students. Table 1 presents the participant profiles. 
Table 1

Participant Profiles

\begin{tabular}{|c|c|c|c|c|c|c|}
\hline Students & s1 & S2 & S3 & S4 & S5 & S6 \\
\hline Gender & $\mathrm{F}$ & $\mathrm{F}$ & $\mathrm{F}$ & $M$ & $M$ & $M$ \\
\hline Age & 21 & 16 & 21 & 15 & 21 & 21 \\
\hline $\begin{array}{l}\text { School } \\
\text { Level }\end{array}$ & University & $\begin{array}{l}\text { High school } \\
-4 \text { th }\end{array}$ & $\begin{array}{c}\text { Vocational } \\
\text { training }\end{array}$ & $\begin{array}{l}\text { High school } \\
-3 \text { rd }\end{array}$ & $\begin{array}{l}\text { Vocational } \\
\text { training }\end{array}$ & College \\
\hline Deafness & $\begin{array}{l}\text { Modarate- } \\
\text { severe }\end{array}$ & $\begin{array}{l}\text { Moderate } \\
\text { (sister - } \\
\text { profound) }\end{array}$ & Profound & $\begin{array}{l}\text { Profound } \\
\text { (sister - } \\
\text { profound) }\end{array}$ & Profound & Profound \\
\hline Device & Hearing aid & Hearing aid & $\begin{array}{l}\text { Cochlear } \\
\text { implant }\end{array}$ & $\begin{array}{l}\text { Cochlear } \\
\text { implant }\end{array}$ & $\begin{array}{l}\text { Cochlear } \\
\text { implant }\end{array}$ & Hearing aid \\
\hline Interpreter & $\begin{array}{c}\text { None } \\
\text { (FM device) }\end{array}$ & $\begin{array}{c}\text { None } \\
\text { (FM device) }\end{array}$ & CS & CS & Pidgin $^{3}$ & Pidgin $^{4}$ \\
\hline $\begin{array}{l}\text { Current Use } \\
\text { of CS }\end{array}$ & & & & $x$ & & \\
\hline $\begin{array}{l}\text { Elementary } \\
\text { Inclusion }\end{array}$ & 1st cycle & 1st cycle & 3rd cycle & 2nd cycle & 3rd cycle & 3rd cycle \\
\hline Parents & P1 & P2 & P3 & P4 & P5 & P6 \\
\hline Learned CS & & & $\mathrm{x}$ & $\mathrm{x}$ & $\mathrm{x}$ & $\mathrm{x}$ \\
\hline
\end{tabular}

\section{Procedure}

To collect information on the participants themselves as well as on their perceptions of their situation, we developed a general information questionnaire and an interview grid. The general information questionnaires allowed us to begin the research interviews with a certain basic knowledge about the participants' experiences. This questionnaire was also useful in modulating the results of the data analysis, as certain external factors might have an influence on perceptions, such as the degree of deafness, modes of communication used at home, and services received.

To collect the most accurate data from participants, we used qualitative semistructured interviews. From an interactionism-based perspective, meaning is not inherent to things, but rather constructed and modified in and through social interactions (Warshay, 1962). This approach allowed us to focus the questions on predefined themes mapped out in our conceptual framework while giving a certain freedom to participants to raise or add any other issues. The topics covered in the interviews included the student's deafness, his or her school and social inclusion experience, and the importance of CS in

${ }^{3}$ Pidgin Sign Language is an approximate mix of oral language and sign language that does not entirely respect the properties and characteristics of either of these methods (Blais, 2000). Usually the vocabulary is drawn from the sign language but follows the oral language word order, and words that do not carry information (e.g., the, to, a, etc.) are often dropped, as are some word endings (e.g., morphemes $-e d,-s,-m e n t$, etc.).

${ }^{4}$ The student had to use Pidgin Sign Language by necessity because the college he was attending refused to hire a CS transliterator; so not having a CS service, he was assigned a Pidgin Sign Language interpreter. 
those processes. For example, the questions presented to the students included: How does deafness affect your daily life? How is your life going in general, at school? Tell me about your schooling: elementary school, high school, college. The questions for parents followed the same general lines.

After agreeing to participate in the study, students and parents were met individually for about 60 minutes each. The purpose of this session was to complete the general information questionnaire and take part in semi-structured interviews that were audiorecorded and subsequently transcribed.

\section{Validation of the Data Collection Steps}

Before the interviews were conducted, the procedures for collecting and processing data were first reviewed by two colleagues with broad experience in research design and then tested with two persons who were not part of the sample because they did not meet the inclusion criteria. This step enabled us to fine-tune certain questions and to confirm that they were useful for the purpose of the study. For instance, we replaced the question, "What role does CS play in your school inclusion and in your social inclusion?" with "What has CS changed in your life?" Unlike the first question, the revised question avoided orienting the respondent toward any specific direction and allowed information to be collected on the respondent's own perceptions about the use of CS. Afterward, the two preliminary interviews were coded and peer-reviewed.

\section{Data Analysis}

Given the qualitative nature of this study, thematic content analysis was the preferred method of analysis because it is useful for describing, clarifying, understanding, and interpreting a situation (Denzin \& Lincoln, 2011; Paillé \& Mucchielli, 2012). As put forward by Paillé and Mucchielli (2012), sequential thematic analysis is partly deductive and partly inductive. In the research process, certain themes emerged from the respondents' statements, while others were theoretically guided by symbolic interactionism and perceptual fields theory. From the point of view of the theory of perceptual fields, out of all the things we might perceive, we perceive what is meaningful to us (Combs, 1999). This perspective allowed us to converge the perceptions of the children and their parents meaningful for them around the use of CS in an inclusion context in order to highlight the themes solicited repeatedly during the interviews.

Two themes emerged from the parents' statements and comprised a first dimension, which was called the personal dimension. The other themes that emerged from our analysis of the participants' statements were grouped either into the social dimension (language development, interactions, and LSQ complementarity) or into the school dimension (academic learning and support, LSQ complementarity, and transliterator services). Figure 1 illustrates the different themes identified by the analysis according to our research design. 
Figure 1. Themes Addressed by the Participants

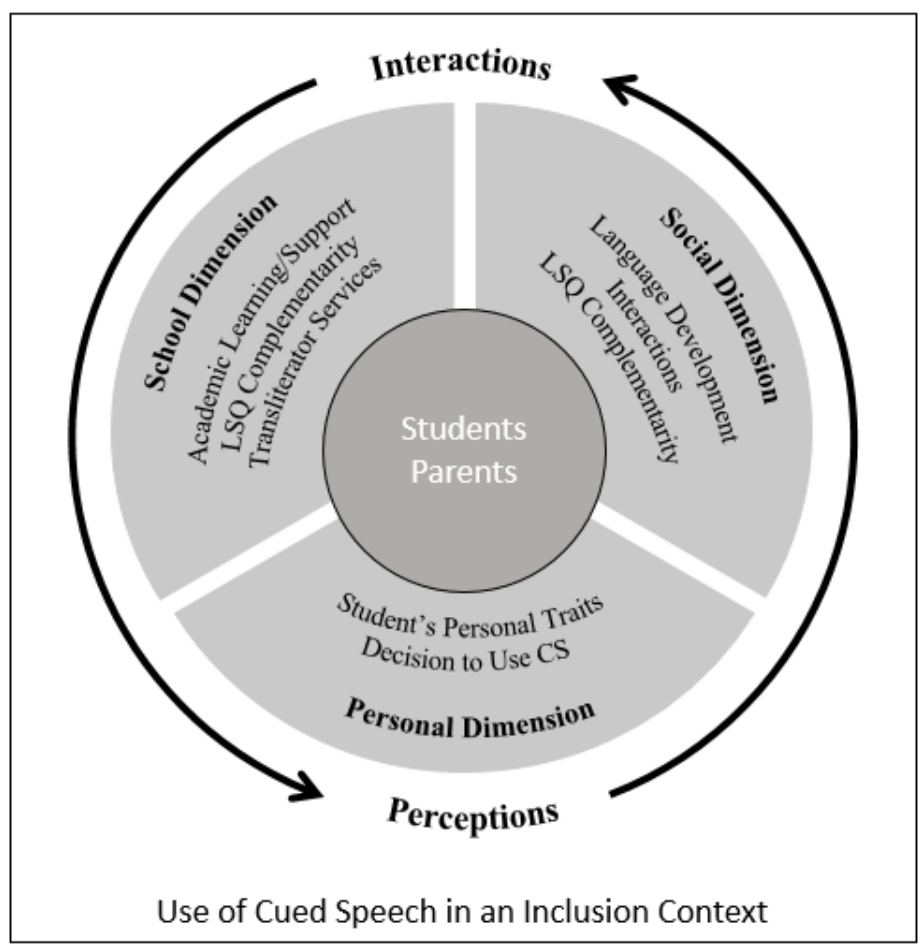

As a methodological precaution in the theme-formulation process, we conducted two check-coding exercises (Miles et al., 2014). The first ensured that the definitions of the themes were sufficiently plausible and relevant, so that another researcher could use the same analysis grid and obtain similar results. The second check-coding exercise was conducted on $10 \%$ of the participants' statements randomly selected for each theme. The rate of agreement obtained before discussion was $82 \%$, with full consensus achieved after discussion. These results corresponded to the recommended level of consistency for check-coding (Miles et al., 2014).

\section{Results}

The data were grouped according to whether the statements were made by students or parents, then were further subdivided into the three dimensions (personal, social, and school) presented in Figure 1.

\section{Personal Dimension}

Two themes that were raised only in the parents' interviews - the decision to use CS and the personal traits of their children - provided a broader picture of the experience of using CS.

Decision to use CS. The decision to use CS was taken before the students' inclusion, but not all the parents felt they had a choice when their child started school. Of the six families encountered, three were nevertheless able to make a decision about their child's 
schooling. Regardless of the type of class (regular or special), it came down to a choice between LSQ or oralism.

That's when we became engulfed in all these questions, LSQ, CS.... Finally, we felt he was starting to catch on a little bit. To be talking. And so the decision was that we would continue with oralism. (P5)

With the learning of oral language supported by CS, some parents felt CS had made real social inclusion possible over the long term. Others, however, did not consider CS to have been very significant in their child's development. Thus, for P1, his child's inclusion mainly had to do with her early entry into the regular school and with the child's characteristics, rather than with the use of a specific communication mode. However, this was not the case for all the families. One family (P3-S3), because of the lack of services for students who are $\mathrm{D} / \mathrm{HH}$ in their school board, had to turn to the only specialized school in the region, which used CS. Thus, these parents really had no choice, as this was the only option within 80 kilometers.

Students' personal traits. Even though this factor was not initially among the themes we identified in the literature on persons who are $\mathrm{D} / \mathrm{HH}$, the parents all spoke about how their child's personality, attitudes, and temperament could have determining influence on their school inclusion.

For P3, her daughter's successful school inclusion was mainly due to her behaviour toward others, and she felt that it was thanks to her daughter's personal traits that she was able to have friends. Other parents saw their child's personal traits as influencing how they performed in school, how they learned, or how they interacted.

For [S4], I would say he had more trouble accepting his deafness than [his deaf sister did].... He had a problem with authority. It doesn't necessarily have anything to do with his deafness, I think, but maybe a little bit, too, I don't know. (P4)

In this statement, it appears that even the acceptance of deafness is part of the attitudes influencing the student's inclusion.

\section{Social Dimension}

In this section, we first present the students' perceptions, followed by those of their parents. The themes addressed by both the students and their parents were language development, the complementary use of LSQ, and interactions.

Students' perceptions. The students explained what CS, in their view, had contributed to their language development. They also spoke about their interactions with interpreters, peers, and teachers, and about the various contexts that characterized these interactions. Lastly, the students spoke about their perceptions of the complementary role of LSQ in their social relationships.

Language development. Regarding the social dimension, respondents indicated that CS fostered interaction especially by facilitating their communications with others, helping them to learn the language, and enabling them to function in an inclusive setting. Along the same lines, all the students noted that CS helped them to be able to say things correctly when speaking orally. 
[CS] has helped me to integrate quickly into communicating verbally with other kids, those kids who knew how to talk well and had good pronunciation.... It helps me talk more. (S1)

For this student, in supporting language development, CS also helped improved interactions with others. Indeed, all the students stressed the importance of being able to speak well. For them, CS was useful in developing oral skills - the form of accurate pronunciation, enhanced vocabulary, improved lip reading, clearer distinctions between sounds with identical labial movements. In fact, this was the primary advantage they identified.

Interactions. The students wanted to be able to do more than just communicate well; they also wanted to make friends and be part of a larger community in which discussions require a good command of language. For some of the students interviewed these interactions involved, among other things, having a transliterator present.

The two students who had the least hearing loss relied primarily on their FM devices to follow what was happening in class (S1, S2). The other four, who had used transliterators, all spoke about their relationships with them, since they often were assigned the same one for several years in a row. For two of them these services were very important in their school socialization, as their transliterators were able to visually translate jokes, stories, or situations that the student had not been able to see. For the other two students, however, the service was a source of disagreement and even of conflict (S3, S4).

It's because my transliterator used to scold my friend, so my friends said, "Hey, why is your transliterator mad at me? It's not my fault." So I had to make excuses for my transliterator, because they were getting mad at me. (S4)

In this particular situation, the professional was confusing different roles, i.e., interpreter, parent, and special educator. The transliterators' approaches varied considerably from one participant to another, and while their experiences were generally positive, it appeared that over the long term a certain amount of adjustment was sometimes required.

Interactions with peers emerged as another key factor. Some students reported feeling excluded because they were $\mathrm{D} / \mathrm{HH}$ and needed more explanations to understand a discussion. As S5 explained, because his deafness was invisible, it did not always occur to his peers to help him when conversations were hard for him to follow; and when he asked questions about what was being said, they made fun of him.

Beyond peer relationships for students who are $\mathrm{D} / \mathrm{HH}$, the interaction between the student who is $\mathrm{D} / \mathrm{HH}$ and his teacher was a core factor in the student's inclusion experience. Participants reported that their relationship with their teacher changed when they were without a transliterator.

I couldn't hear anything.... I didn't have my transliterator. So then, the teacher, she would always get irritated when I asked questions.... She even asked my mother to keep me at home because there was just one more day before the transliterator was coming back. (S4) 
Other students we interviewed experienced quite the opposite situation, in which the teacher became more attentive to make up for the transliterator's absence. For S3, when she did not have a transliterator, the teacher spent extra time to help her understand everything being taught in class.

Of the two students who used FM devices, S1 reported that teachers sometimes resisted wearing the microphone, which made lip reading difficult for her. This student, as did S4, also considered that the teacher had a certain power over her ability to succeed and felt she was not being supported academically. Nevertheless, all the students reported that, as the school year progressed, they felt increasingly integrated into their environments and sometimes had the impression that their deafness was forgotten.

Complementary use of LSQ. All the students interviewed had some knowledge of LSQ to different degrees. Two (S4, S5) learned basic LSQ in early childhood, right up into kindergarten, before starting to learn CS. Others learned it by spending time in the company of other children who are $\mathrm{D} / \mathrm{HH}$ and who used LSQ, either in associations or at summer camps. The students interviewed had very clear ideas about when to use CS and when to use LSQ. LSQ was used for rapid interactions with others who knew signs (camp counsellors, transliterators, friends who are $\mathrm{D} / \mathrm{HH}$ ), whereas $\mathrm{CS}$ required a command of oral language and was primarily a support for academic activity.

During their interview, on the one hand, all students reported using CS as an educational tool in school to facilitate language development, to help make their speech be more intelligible, and, as discussed in the subsection School Dimension, to improve their understanding of academic content. LSQ, on the other hand, was described as more a mode for communicating among people who are $\mathrm{D} / \mathrm{HH}$. Even the four students who had not formally learned LSQ (S1, S2, S3, S6) reported using it with their school transliterator to speed up the interpretation, or in conversations with their friends who are $\mathrm{D} / \mathrm{HH}$. They found LSQ easy to learn because it was often based on images that represented concepts. Since CS is based on sounds, where students who are D/HH cannot necessarily hear, learning CS phonology cues seems more difficult than learning LSQ. Yet even though LSQ is a more accessible communication mode for these students, they see it as another element of exclusion because, in a hearing world, it cannot be used in interactions with other students who do not know LSQ.

I had been in the Deaf community and I had liked that. I had learned LSQ and then, coming into high school, I felt all alone among all these [hearing] people.... I had a major identity crisis, figuring out what group I belonged to. I think it's too bad, because I tell myself, there's a Deaf community and a hearing community.... It's a little like immigrants who come here. (S1)

In this statement, the student concluded that to be able to function equally well in both settings and be fully integrated, the person must master two languages and two cultures. This perspective may explain why all the students in this study appreciated interacting with ease in either situation.

Parents' perceptions. Like the students, the parents highlighted the contribution of CS to their children's language development; and even though its use was variable, they considered it to be useful in learning oral language and in their interactions. 
Language development. Similar to their children, the parents also addressed the theme of language development. While the outcomes differed from one student to another, all the parents said that learning CS had helped their children to a better understanding of oral language, but also to express themselves.

When [S2] started school, she couldn't say her name.... She would put a $j$. And I remember trying to get her to say a $d$, but she would say dje. She couldn't hear it. With CS, she learned to put syllables on words. To talk better. (P2)

P2 saw the impact of learning CS initially in the process of learning oral language. To promote their children's language development, two parents (P5, P6) made an effort to use CS at home and two others (P3, P4) used it systematically. This enabled them to communicate with their children and helped the children to distinguish between different sounds.

One parent (P6) explained that even though she found it difficult to become fluent in CS, it was a good tool for explaining word pronunciation to her son, but only when needed. For two families (P3, P5), it was with CS that their child began to speak. In the other families, the language of the child who is $\mathrm{D} / \mathrm{HH}$ improved through clearer pronunciation or sentences. The parents who had used CS in the home reported that, while they used it fairly regularly when their child started elementary school, its use became more sporadic over the years, to the point at which those families were no longer using it at the time of our study. This illustrates the temporary nature of CS, in that it is used only until the student achieves a certain level of mastery in oral and written language.

Interaction with school personnel. Some parents found that the oral-language professionals sometimes put a lot of pressure on them to learn CS.

I remember, I drove [S5] back [to school], and there, I used some signs. She [the teacher] nearly blew up at me ... [saying] that if I wanted him to use oral language, I had to stop using signs, and that I was pretty much an unfit mother. (P5)

Thus, from what P5 said, some high school teachers were not very supportive of complementarity between CS and LSQ, as they were not in favour of using LSQ at home while the student was learning CS in school.

All the parents spoke about the various measures they took, in the inclusive setting, to make school personnel more conscious of their child's needs. For P1, this involvement manifested itself in a collect of tennis balls to reduce the noise generated by the scuffling of chairs in her daughter's classroom so that she could optimize the use of her hearing aids. For other parents, this involvement took the form of leading consciousness-raising workshops in regular classes to explain to the group and the teacher the difficulties experienced by the child who is $\mathrm{D} / \mathrm{HH}$. The parents in our study explained that it was mostly in their children's first years at school that these types of interventions were needed. Often such interventions were needed to deal with teachers who were inflexible or refused to use FM devices, as described by S1 (subsection Students' perceptionsInteractions). Nonetheless, P6 explained a contrasting experience in which a teacher ensured her child's success.

Complementary use of $\boldsymbol{L S Q}$. Three of the parents interviewed (P2, P4, P5) had learned LSQ and, like their children, readily saw its usefulness in the context of social 
interactions. For two of these parents, when they learned LSQ it became the primary mode of communication with their child (P4, P5), and they had to use sign language to interact with their child and understand his or her needs. Despite this, when their children were in kindergarten, these three parents all decided to have them educated in an orallanguage approach to prepare them for life in a hearing society.

The more he develops himself among hearing [students], the better it will be for him.

You know, his family is hearing, everyone is hearing around him, you know. (P5)

For this family (P5-S5), the change from LSQ-based to CS-facilitated oral-language schooling did not have the support of the speech therapists in their rehabilitation centre. After a short try in a LSQ class, even though they were going against the educators' advice, these parents decided to move their son from a specialized LSQ classroom to a school specialized in CS when they saw that he was not being stimulated as much as the other students in his class. However, learning CS did not stop this family from continuing to use LSQ at home, as this was the communication method they had been using all along.

\section{School Dimension}

With regard to the school dimension, both the parents and the students described how CS had influenced their academic experiences.

Students' perceptions. The students talked about interpreter services, not only with regard to mastering the CS cues, but also more generally about the availability of services. The students also explained how LSQ was used in a complementary way for school purposes.

Academic learning. In terms of academics, for students, the major advantage of CS was that it enabled them to understand and differentiate between sounds, and thereby to follow the curriculum in a regular school. All the students reported that this learning of the "correct" words or spellings happened mostly in elementary school. For the four students who used CS in high school, French was the subject it was mainly used in, both to understand what was being said and to learn writing skills. S3 explained that in French classes, CS is better than sign language because with CS you make whole sentences, unlike sign language where the words used are not as specific. However, this support is less useful in subjects such as mathematics or science.

In high school, it was more complicated. The interpreter had to use [LSQ] signs. Because there were teachers who talked a lot. It was different.... For French especially, we did, we often used CS. It was important. For other subjects, no. For instance in math, we used [LSQ] signs. (S4)

Once the student knows the vocabulary, it is faster to make the sign for the number four, for example, than to cue it. It is true that CS transliterators are usually able to match the pace of spoken language, but this depends very much on the speed of the teacher's talking, and in some situations knowing sign language is a significant asset in interpretation.

Complementarity use of LSQ. Because LSQ uses fewer signs (as compared to CS codes) and a different syntax than oral language, its interpretation is usually much more rapid than CS. Thus, as the students explained, in courses in which the teacher speaks 
rapidly, even a CS transliterator tends to use LSQ to be able to keep up. However, this does not happen in every situation, but occurs more often in some subjects than in others. This CS-LSQ complementarity is ultimately based on the premise that the overriding goal is to ensure students understand all the concepts explained in class, the vocabulary being used, and what it means, before they can combine CS with sign language.

It depends what you're saying. It's because the transliterators, they mix things up a little. They use more CS, but they put signs in there, too. It's like with writing, there are attached [cursive] and unattached [printed] letters. It's a little bit like that.... Yes, sometimes, to keep up, you need to sign. (S4)

Thus, the students used the two modes of communication very consciously. In these situations the student also needs to be able to understand LSQ, because conveying the information in this format must not impede the student's learning.

Transliterator services. Of the six students interviewed, four used transliterator services in high school. For them the interpreter's presence was sometimes essential, not only for understanding what the teacher was saying, but also for gaining access to what was said in class by the other students. Without this added input, their learning would have been affected. For example, when the teacher wrote on the board only the important points of the content, leaving out spoken details, S4 noticed that without transliterator services he tended to miss a lot of material. However, for the transliterator service to be effective, it needs to be compatible with the student's needs. Because CS transliterators are hard to find, sometimes students are given sign or oral interpreters. In both cases, since these interpreters do not meet the student's need for a CS transliterator, the student may be at risk of failing courses.

In French, I tried with a LSQ interpreter, she was a replacement assigned to me. And when we did activities using LSQ, I failed completely. (S6)

Students S3, S4, and S5 made the same observation regarding transliterators who were not properly trained or sufficiently knowledgeable in CS. Because CS is not the same in English as it is in French, not only did the CS transliterators have to know the English cue chart for the English classes, but the students also had to know it well enough to understand the transliterator's cues. ${ }^{5}$ Two students (S3, S4) spoke about their problems with CS in English.

Especially in English, it's hard.... My transliterator last year, she could do that. She did [CS] in English, but she didn't understand that I didn't understand it.... The sounds didn't work..... They didn't teach me that when I was little. (S4)

Students therefore need to know oral French and the French cue chart, as well as English CS, to understand English phonemes. For students who are D/HH, who are from the outset at a disadvantage in learning language, this constitutes an additional burden.

Parents' perceptions. With regard to school, the parents' perceptions about the use of CS revolved around two points: academic support, which refers to their support for their child's school work; and interpreter services, which refers to all the efforts expended by parents to obtain these services for their child.

\footnotetext{
${ }^{5}$ English as a second language is mandatory in Quebec to obtain the Secondary School Diploma.
} 
Academic support. The parents who had learned CS explained that they used it primarily in supporting their child's school work. However, their use of CS was limited to the early school years, and some of the parents found it difficult to use CS at home. Now that their child had been integrated, some of the parents saw CS as simply an educational tool that their child no longer needed.

Transliterator services. In all, of the four families who had used transliterator services in school, two of those families had to find interpreter services when their children went on to vocational training after high school (S3, S5). These two families explained that, unlike in high school, where interpreter services are provided by the school board, when students go into post-secondary training the family is responsible for hiring interpreters, for which there are government subsidies. For parent P5, this entailed several conflicts. First, she was unable to find an interpreter with a good command of CS, and then the student noticed that the transliterator was not transmitting everything the teachers said. Finally, the transliterator would be absent without advising the student. In this case, the parent had to assume a threefold role of parent, employer, and service coordinator, and the scarcity of transliterators did not help.

In another case, the lack of appropriate CS transliterator services prompted parent P3 to push her daughter to stay in school and to learn to function without services. She saw this as putting her daughter in the real-life situation of being in a hearing society. For this parent, not having an interpreter allowed her daughter to put her knowledge of oral language to the test and to be fully immersed in the inclusion experience. According to this parent, it was during this period that her daughter, S3, learned strategies and techniques that enabled her later to be fully integrated into her actual work environment.

\section{Discussion}

Our objective in this study was to describe the perceptions of students who are $\mathrm{D} / \mathrm{HH}$ and of their parents regarding the use of CS in an inclusion context and then to identify factors that might influence those perceptions. In the end, it is interesting to note that the participants did not talk about CS per se, but rather about all the interactions that affect its use: relationships with peers, transliterators, and teachers. According to the notion of perceptual fields (Combs, 1999), these interactions were the source of countless perceptions that sometimes supported school and social inclusion and at other times were impediments. The results revealed certain points on which the participants' perceptions converged: (a) CS is helpful in developing oral and written language and is a means of inclusion; (b) the use of CS is temporary and should be adapted to the context; (c) CS interpreter services are often difficult to obtain; and (d) LSQ can be used to complement CS.

There were no divergent perceptions about CS use; only the respondents' experiences were different. The emergent themes mostly had to do with conditions that fostered or hindered the students' inclusion at school. These conditions corresponded to the second part of our objective, which was to identify the factors shaping these perceptions. The three emergent themes had to do with: (a) the inclusion environments shaped by the educators; (b) the decision to use CS; and (c) the students' personal traits. In this section, we present our results by first discussing the convergences identified among the perceptions and then examining the factors influencing them. 


\section{CS as a Support to the Development of Oral and Written Language and as a Means of Inclusion}

Whether looking at it from the social or the school perspective, all the parents and the students considered CS to be an essential support for developing oral language and learning to write. This result corroborates those of other studies on this subject (LaSasso \& Crain, 2010; Leybaert et al., 2011). The originality of our study lies in the fact that it was focused on the context within which CS is used, rather than on its didactic outcomes. At the same time, we answered to "an urgent need for further research concerning interventions that promote social interactions [of students who are $\mathrm{D} / \mathrm{HH}$ ] in inclusive education" raised by Xie, Potměšil, \& Peters (2014, p. 435). Even though the parents and students did not draw explicit links between CS and the inclusion context, CS appears to support a student's inclusion, so long as it responds to a specific need in that student and the conditions for its implementation are respected (quality and availability of interpreter services, educators' open and supportive attitudes).

According to participants, by developing oral language these children were then better able to integrate into a hearing society. These results were similar to those obtained by Crain and LaSasso (2010), who pointed out that CS had had an impact on the participants' lives, especially in the areas of communication, language, access, and academic success, as well as in terms of self-esteem. Nonetheless, two families whose children had the least profound hearing losses and had used CS for the shortest time (one or two years), had little or nothing to say about whether CS was useful in inclusion. These two children (S1 and S2) were nevertheless successfully integrated into regular classes, which suggests that CS might be a springboard to inclusion only for some children, and not necessarily for others.

Our results in this respect are aligned with those of several different studies (Aparicio et al., 2012; LaSasso \& Crain, 2010; Leybaert et al., 2011; Leybaert \& LaSasso, 2010). Once they had passed the critical stage of language learning and were integrated into high school, the students used CS almost exclusively through their transliterators. This is probably why the students and parents no longer saw CS as a tool for language development, but only as a support measure to compensate for what they might miss in the oral environment in the classroom.

\section{CS as a Temporary Tool Adapted to Context}

Along the same lines, another observation had to do with the temporary nature of CS use, at home and/or at school, regardless of the student. For those who did not use transliterators, its use was more temporary than for others who were still using CS at school. This is a somewhat new research finding, as we found no similar results in the literature. While some studies have observed that CS is only used in school (Leybaert et al., 2011), the temporary nature of this support measure has not been explored, nor the reasons why it is used only in school. Our study uncovered two reasons why its use was limited to school: first, because the students no longer needed CS in the home to do their homework; and second, because it was difficult for hearing persons to learn it with sufficient fluency. Thus, even if some students continued to use CS transliterators in class 
to ensure they captured all the required information, CS was no longer necessary outside of class because these students had a good command of oral and written language.

\section{CS Interpreter Services Are Often Difficult to Obtain}

All the families we interviewed who had used transliterators emphasized clearly and strongly the fact that CS transliterators are in short supply, and that the way interpreter services are organized is not always in the students' best interests. In an academic environment where CS transliterators are a rare commodity, it is sometimes difficult for students who are $\mathrm{D} / \mathrm{HH}$ to obtain the types of services they need: Interpreters are sometimes not trained in CS; interpreters are assigned to students based on union seniority rather than on fit between their qualifications and students' needs; and in postsecondary vocational programs, families, rather than school boards, are responsible for hiring interpreters or transliterators. These problems were also highlighted in the work of LaSasso and Crain (2010), and of Parisot, Villeneuve, Daigle, and Missud (2008). Since this latest Quebec study, the situation does not seem to have improved for students needing a CS transliterator.

\section{LSQ Used to Complement CS}

In our study, even though the use of LSQ was not formalized, the students' situation constituted a form of bilingualism, in which CS and LSQ were both being used in high school but for different purposes (Hauser, 2000; Kyllo, 2010; Morales-López, 2008). It is true that we did not assess the students' skills in LSQ, and it may be that the LSQ they used was more akin to a Pidgin Signed French. ${ }^{6}$ Still, it seemed the students had learned LSQ informally out of necessity, partly because some interpreters or transliterators were more comfortable with LSQ than with CS or had to speed up interpretation, and partly from having interacted with other students who are $\mathrm{D} / \mathrm{HH}$ who used signs (e.g., in associations, summer camps). In social interactions, knowing both LSQ and oral language was useful in enabling students to engage in whatever communication mode was best suited to the other person. However, because the students were using LSQ without having studied it formally, there was the possibility that they might not properly understand what was being signed in LSQ (by the interpreter or by other students), with the attendant risk that such a misunderstanding might negatively affect their academic results or interactions.

\section{Inclusion Environments Shaped by Educators}

Across the province of Quebec, even though CS is gradually becoming better known, its implementation is still limited. However, to achieve students' inclusion requires that certain conditions be put in place. Among the themes raised by our respondents, interactions with teachers and other school professionals seemed to be a major factor in students' successful inclusion and in the implementation of adapted services. Moreover, various studies have identified certain conditions that must be put in

${ }^{6}$ See footnote, Table 1. 
place to foster the inclusion of students who are D/HH (Eriks-Brophy et al., 2006; Powers, 2002); chief among these are professional training and collaboration among school personnel. Indeed, an educator whose attitude toward students is positive (open, receptive, attentive, supportive, listening, etc.) will foster successful inclusion. This is one of the main factors identified in the literature as influencing a student's successful inclusion (Eriks-Brophy et al., 2006; Nilholm \& Alm, 2010).

\section{Decision to Use CS}

The decision to use CS was not perceived in the same way by the different parents interviewed. Some felt they had no choice, because there were no other services for the students who are $\mathrm{D} / \mathrm{HH}$ in their region. Others were faced with a choice between two communication methods: sign language or oralism. In other studies on selecting a communication mode for those who are $\mathrm{D} / \mathrm{HH}$, the two considerations most often cited have been geographic location and learning oral language (Crain \& LaSasso, 2010; EriksBrophy et al., 2006; Reynolds, 2007), findings which coincide precisely with our own results.

\section{Students' Personal Traits}

A final aspect, which was frequently mentioned by the parents, was the students' personal traits. It is true that deafness is often associated with behaviours expressing frustration, isolation, problematic interactions, or difficulty in forming friendships (Kunnen, 2014; Marschark \& Leigh, 2016). However, when parents compared their child with others, they saw beyond these characteristics associated with deafness, and considered their child's personality to be a determining factor in whether he or she would succeed in school and be well integrated socially. In light of this finding, the parents' perceptions of the use of CS and of their children's inclusion appeared to have been shaped by the students' own efforts, motivation, and competencies. According to studies on the disability creation process, personal traits such as temperament, personality, and attitudes are among the factors influencing successful inclusion, which is one manifestation of social participation (Geyh et al., 2011). This last point seems to have received only little attention in the research on deafness. While Powers (2002) highlighted three factors related to students that could foster their inclusionextracurricular activities, involvement in decisions, and success in school- he did not address the students' own traits. Indeed, we were unable to find any studies on students who are $\mathrm{D} / \mathrm{HH}$ in which personal traits were discussed as factors that could influence inclusion. Research on this topic is warranted.

\section{Conclusion}

According to the perceptions of students and their parents in this study, there is no direct link between CS use and inclusion; CS seems to have indirectly supported inclusion by facilitating the learning of oral language. For our participants, successful inclusion depended more on the interactions among the different actors than on the use of one particular communication mode. From these results, therefore, it should be noted that inclusion is fostered by encouraging awareness-raising in regular schools, among both 
students and teachers, and by supporting the students' learning in a variety of ways (CS, FM device, special accommodations, remedial education, etc.). It should also be noted that inclusion in high school supports social inclusion, which can be expressed in ways that no longer depend on CS. This implies that measures adopted to support students need to evolve as their needs change, so as not to impede their interactions with others. Seen through the lens of the participants' perceptions, the different communication modes - oral language, CS, and LSQ - can be conceived as complementary, depending on the situation.

This study has certain limitations, which should be mentioned. First, all the students we interviewed had been integrated; if this had not been the case, the conclusions might have been different. Also, all the students interviewed used hearing aids or had cochlear implants, and while some of them were profoundly deaf, they nevertheless had a certain auditory acuity. Some studies have shown that the use of hearing aids or cochlear implants has an impact on language learning and communication (Dammeyer, 2010; Le Normand, Simon, \& Leybaert, 2014; Leybaert \& LaSasso, 2010). Given this, it is conceivable that the students' cochlear implants and hearing aids could also have had an impact on their inclusion.

Of course, given the small number of participants, the results cannot be generalized. It is also possible that, due to social desirability bias or the influence of recent events, some parents or students may have expressed opinions that did not reflect what they usually thought. Perceptions are indeed subject to the influences of time and other events, such that the perceptions expressed in our interviews could change yet again. It is also possible that other factors not considered in our analysis may have affected the perceptions we collected. For instance, the parents' education level and socio-economic status might also have had an impact on their child's language development or academic achievement (de Boer, Pijl, \& Minnaert, 2010; Finnie, Childs, \& Wismer, 2011; Hoff, 2012).

This study identified certain factors that influence perceptions regarding CS use in inclusion, considering, in particular, interactions with school personnel. In Quebec, high school teachers are trained first and foremost in a didactic model, that is, they are primarily trained in the subject matter they will be teaching; they receive very little preparation for dealing with students with special needs or, even less, students who are $\mathrm{D} / \mathrm{HH}$. Unless they receive specific additional training, teachers know very little about the educational and learning needs of students who are $\mathrm{D} / \mathrm{HH}$. Therefore, there is a fundamental need to raise awareness in schools attended by students who are $\mathrm{D} / \mathrm{HH}$. Awareness-raising activities need to take place more than just once a year, to bring teachers up-to-date and ensure their interventions remain appropriate. Interpreter training also needs to be updated to include more CS, and, at the very least, the allocation of assignments in schools needs to be revised so that students' needs have priority over interpreter seniority. Consequently, any school board wishing to integrate students who are deaf of hard of hearing using CS must take into account, first of all, the students' needs, the availability and competency of interpreters, and the attitudes of the school personnel working with those students.

In our study, we looked at interactions through the lens of students' and parents' perceptions. Many respondents spoke about teachers', interpreters' and specialists' attitudes toward the students, that is, how they taught, how they worked with the students, 
whether or not they offered advice, etc. This suggests that our respondents saw these interventions as being important. We did not, however, look at what the school personnel thought. It may be that, by exploring their perceptions, we could better understand student-educator and parent-educator interactions and the reactions coming out of them, and form a clearer picture of the role of CS in students' inclusion.

\section{References}

Angelides, P., \& Aravi, C. (2007). A comparative perspective on the experiences of deaf and hard of hearing individuals as students at mainstreaming and special schools. American Annals of the Deaf, 151(5), 476-487. doi:10.1353/aad.2007.0001

Aparicio, M., Peigneux, P., Charlier, B., Neyrat, C., \& Leybaert, J. (2012). Early experience of Cued Speech enhances speechreading performance in deaf. Scandinavian Journal of Psychology, 53(1), 41-46. doi:10.1111/j.1467-9450.2011.00919.x

Blais, Y. (2000). L'importance de l'interprétation en langage visuel dans l'intégration des élèves vivant avec une surdité. Apprentissage et socialisation, 20, 67-81.

Blumer, H. (1962). Society as symbolic interaction. In A. M. Rose (Ed.), Human behavior and social processes (pp. 179-192). Boston, MA: Houghton Mifflin.

Blumer, H. (1969). Symbolic interactionism. Perspective and method. Englewood Cliffs, NJ: PrenticeHall.

Canada Statistics. (2010). Participation and activity limitation survey 2006. (89-628-X no. 012). Ottawa, ON: Canada Statistics.

Combs, A. W. (1999). Being and becoming: A field approach to psychology. New York, NY: Springer Publishing.

Combs, A. W., Richards, A. C., \& Richards, F. (1976). Perceptual psychology. A humanistic approach to the study of persons. New York, NY: University Press of America.

Combs, A. W., \& Snygg, D. (1959). Individual behavior: A perceptual approach to behavior. New York, NY: Harper \& Row.

Cornett, R. O. (n.d.). International languages/dialects. Adapting Cued Speech to additional languages [Webpage]. Retrieved from the website of the National Cued Speech Association, http://www.cuedspeech.org/cued-speech-in-different-languages

Crain, K. L., \& LaSasso, C. J. (2010). Experiences and perceptions of cueing deaf adults. In C. LaSasso, K. L. Crain, \& J. Leybaert (Eds.), Cued Speech and Cued Language for deaf and hard of hearing children (pp. 183-216). San Diego, CA: Plural Publishing.

Dammeyer, J. (2010). Psychosocial development in a Danish population of children with cochlear implants and deaf and hard-of-hearing children. Journal of Deaf Studies and Deaf Education, 15(1), 50-58. doi:10.1093/deafed/enp024

de Boer, A., Pijl, S. J., \& Minnaert, A. (2010). Attitudes of parents towards inclusive education: A review of the literature. European Journal of Special Needs Education, 25(2), 165-181. doi:10.1080/08856251003658694

Denzin, N. K., \& Lincoln, Y. S. (2011). The SAGE handbook of qualitative research (4th ed.). Thousand Oaks, CA: SAGE Publications.

Dupont, A. (2009). Perceptions d'élèves québécois présentant une déficience auditive de l'utilisation du langage parlé complété en contexte d'intégration scolaire (Master's thesis). Université de Montréal, Montréal, QC. 
Dupont, A. (2018). Regards croisés sur l'intégration scolaire d'élèves sourds utilisant la langue parlée complétée: Perceptions d'élèves, de parents et d'enseignants (Doctoral dissertation). Université de Sherbrooke, Sherbrooke, QC.

Eriks-Brophy, A., Durieux-Smith, A., Olds, J., Fitzpatrick, E., Duquette, C., \& Whittingham, J. (2006). Facilitators and barriers to the inclusion of orally educated children and youth with hearing loss. The Volta Review, 106(1), 53-88.

Finnie, R., Childs, S., \& Wismer, A. (2011). Accès à l'éducation postsecondaire: Comparaison entre l'Ontario et d'autres régions. Toronto, ON: Conseil ontarien de la qualité de l'enseignement supérieur.

Geers, A., \& Moog, J. (1989). Factors predictive of the development of literacy in profoundly hearingimpaired adolescents. Volta Review, 91(2), 69-86.

Geyh, S., Peter, C., Müller, R., Bickenbach, J. E., Kostanjsek, N., Üstün, B. T., ... Cieza, A. (2011). The personal factors of the international classification of functioning, disability and health in the literature-A systematic review and content analysis. Disability and Rehabilitation, 33(13-14), 1089-1102. doi:10.3109/09638288.2010.523104

Gouvernement du Québec. (2011). Loi sur l'instruction publique. Québec, QC: Éditeur officiel du Québec.

Hauser, P. C. (2000). An analysis of codeswitching: American Sign Language and Cued English. In M. Metzger (Ed.), Bilingualism and identity in Deaf communities (vol. 6, pp. 43-78). Washington, DC: Gallaudet University Press.

Hoff, E. (2012). Causes and consequences of SES-related differences in parent-to-child speech. In M. H. Bornstein \& R. H. Bradley (Eds.), Socioeconomic status, parenting, and child development (pp. 147-158). New York, NY: Routledge.

Kunnen, E. S. (2014). Identity development in deaf adolescents. Journal of Deaf Studies and Deaf Education, 19(4), 496-507. doi:10.1093/deafed/enu010

Kyllo, K. L. (2010). A bilingual (ASL and Cued American English) program for Deaf and hard of hearing students: Theory to practice. In C. LaSasso, K. Crain, \& J. Leybaert (Eds.), Cued Speech and Cued Language for deaf and hard of hearing children (pp. 217-241). San Diego, CA: Plural Publishing.

LaSasso, C. J., \& Crain, K. L. (2010). Cued Language for the development of deaf students' reading comprehension and measured reading comprehension. In C. LaSasso, K. Crain, \& J. Leybaert (Eds.), Cued Speech and Cued Language for deaf and hard of hearing children (pp. 285321). San Diego, CA : Plural Publishing.

LaSasso, C. J., \& Crain, K. L. (2015). Reading for deaf and hearing readers: Qualitatively and/or quantitatively similar or different? A nature versus nurture issue. American Annals of the Deaf, 159(5), 447-467. doi:10.1353/aad.2015.0004

Le Normand, M. T., Simon, M., \& Leybaert, J. (2014). Spoken language and literacy skills in Frenchspeaking children with cochlear implants: A 5-year follow-up study. International Journal of Speech \& Language Pathology and Audiology, 2(1), 27-39. doi:10.12970/23111917.2014.02.01.4

Leybaert, J., Aparicio, M., \& Alegria, J. (2011). The role of Cued Speech in language development of deaf children. In P. E. Spencer (Ed.), Oxford handbook of Deaf studies, language, and education (2nd ed., vol. 1, pp. 276-289). New York, NY: Oxford University Press.

Leybaert, J., \& LaSasso, C. J. (2010). Cued Speech for enhancing speech perception and first language development of children with cochlear implants. Trends in Amplification, 14(2), 96112. doi: $10.1177 / 1084713810375567$ 
Miles, M. B., Huberman, A. M., \& Saldaña, J. (2014). Qualitative data analysis: A methods sourcebook (3rd ed.). Thousand Oaks, CA: SAGE Publications.

Ministère de l'Éducation du Loisir et du Sport. (2009). Effectif étudiant à l'éducation préscolaire, primaire et secondaire. Québec, QC : Gouvernement du Québec. Retrieved from http://www.mels.gouv.qc.ca/sections/publications/index.asp?page=fiche\&id=753

Ministère de l'Éducation du Loisir et du Sport du Québec. (2010). Rencontres des partenaires en éducation-Document d'appui à la réflexion-Rencontre sur l'intégration des élèves handicapés ou en difficulté. Québec, QC: Gouvernement du Québec.

Mitchell, R. E., \& Karchmer, M. A. (2004). Chasing the mythical ten percent: Parental hearing status of deaf and hard of hearing students in the United States. Sign Language Studies, 4(2), 138163. doi:10.1353/sls.2004.0005

Morales-López, E. (2008). Sign bilingualism in Spanish deaf education. In C. Plaza-Pust \& E. Morales-López (Eds.), Sign bilingualism: Language development, interaction, and maintenance in sign language contact situations (pp. 223-331). Philadelphia, PA: John Benjamins B. V.

Nicholls, G. H., \& Ling, D. (1982). Cued Speech and the reception of spoken language. Journal of Speech and Hearing Research, 25(2), 262-269. doi:10.1044/jshr.2502.262

Nilholm, C., \& Alm, B. (2010). An inclusive classroom? A case study of inclusiveness, teacher strategies, and children's experiences. European Journal of Special Needs Education, 25(3), 239-252. doi:10.1080/08856257.2010.492933

Office des personnes handicapées du Québec. (2005). État de la situation de la langue des signes québécoise. Drummondville, QC: Office des personnes handicapées du Québec.

Paillé, P., \& Mucchielli, A. (2012). L'analyse qualitative en sciences humaines et sociales (3rd ed.). Paris, France: Armand Collin.

Parisot, A.-M., Villeneuve, S., Daigle, D., \& Missud, A. (2008). Rapport de recherche déposé au comité de travail sur la formation et l'évaluation des interprètes visuels. Université du Québec à Montréal, QC: Groupe de recherche sur la LSQ et le bilinguisme sourd.

Périer, O., Charlier, B., Hage, C., \& Alegría, J. (1990). Evaluation of the effects of prolonged Cued Speech practice upon the reception of spoken language. Cued Speech Journal, 4, 47-59.

Powers, S. (2002). From concepts to practice in deaf education: A United Kingdom perspective on inclusion. Journal of Deaf Studies and Deaf Education, 7, 230-243. doi:10.1093/deafed/7.3.230

Reynolds, S. E. (2007). An examination of Cued Speech as a tool for language, literacy, and bilingualism for children who are deaf or hard of hearing (Master's thesis). Washington University School of Medicine, St. Louis, MO.

Schoenborn, C. A., \& Heyman, K. (2008). Health disparities among adults with hearing loss: United States, 2000-2006. CDC/NCHS National Health Interview Survey, 2000-2006, Health EStat, $1-14$.

Xie, Y.-H., Potměšil, M., \& Peters, B. (2014). Children who are deaf or hard of hearing in inclusive educational settings: A literature review on interactions with peers. Journal of Deaf Studies and Deaf Education, 19(4), 423-437.

\section{Authors' Note}

Correspondence concerning this article should be addressed to Audrey Dupont. Email: audrey.dupont@umontreal.ca 